\title{
Emerging role of aripiprazole for treatment of irritability associated with autistic disorder in children and adolescents
}

REVIEW

This article was published in the following Dove Press journal:

Adolescent Health, Medicine and Therapeutics

16 September 2010

Number of times this article has been viewed

\author{
Joan Stachnik \\ Michael Gabay \\ Department of Pharmacy Practice, \\ College of Pharmacy, University \\ of Illinois at Chicago, Illinois, USA
}

Correspondence: Joan Stachnik Department of Pharmacy Practice, College of Pharmacy, University of Illinois at Chicago, 833 SWood Street (M/C 886), Chicago, IL 606 I2, USA

Tel + I 3I2 4I 37699

Fax +I 3129960448

Email stachnik@uic.edu

\begin{abstract}
Autistic disorder is a largely misunderstood and difficult to treat neurodevelopmental disorder. Three core domains of functioning are affected by autistic disorder, ie, socialization, communication, and behavior. Signs of autistic disorder may be present early, but are frequently overlooked, resulting in a delay in its diagnosis and a subsequent delay in treatment. No one definitive therapy is available, and treatment consists of early educational and behavioral interventions, as well as drug therapy. Atypical antipsychotics have often been used in the treatment of autistic disorder to target irritability, aggression, and self-injurious behavior, all of which can interfere with other aspects of treatment. One atypical antipsychotic, aripiprazole, has recently been approved for treatment of irritability associated with autistic disorder. Based on the results from two randomized, controlled trials, with efficacy data from nearly 300 patients, treatment with aripiprazole was associated with reductions in irritability, global improvements in behavior, and improvements in quality of life from both the patient and caregiver perspectives. Dosage of aripiprazole ranged from $5 \mathrm{mg}$ to $15 \mathrm{mg}$ per day. Aripiprazole was well tolerated during clinical trials, with most adverse events considered mild or moderate. Clinically relevant weight gain occurred in about $30 \%$ of patients given aripiprazole, although when compared with other atypical antipsychotics, aripiprazole appears to have fewer metabolic effects and a lower risk of weight gain. However, pediatric patients taking any atypical antipsychotic should be carefully monitored for potential adverse events, because the long-term effects of antipsychotic therapy in this population are not well known. When used appropriately, aripiprazole has the potential to be an effective treatment for children with autistic disorder to improve irritability and aggressive behavior and improve quality of life.
\end{abstract}

Keywords: autism, autistic disorder, aripiprazole, atypical antipsychotics

\section{Introduction}

Autistic disorder is a challenging condition for patients, families, and health care providers. Diagnosis of the disorder is difficult and often delayed, taking up to five years in some cases. ${ }^{1-3}$ Lack of awareness of the disorder by physicians, the wide spectrum of symptoms associated with autistic disorder and its continuous nature, and the young age at which autistic disorder presents, all contribute to this difficulty and delay. Once diagnosed, treatment of autistic disorder is also difficult. Educational and behavioral interventions, if initiated early, can be effective. In addition, pharmacologic therapy has been used to treat symptoms associated with autistic disorder, primarily relating to behavior. However, there appears to be few definitive treatments. Antipsychotics, both conventional and atypical, have been used for aggressive or potentially self-harmful 
behaviors. ${ }^{4,5}$ One atypical antipsychotic, aripiprazole, was recently approved to treat irritability associated with autistic disorder. This paper will provide an overview of autistic disorder, with a focus on aripiprazole as a treatment option.

\section{Autistic disorder}

Autistic disorder, or autism, was first described in 1943 by Kanner, based on the observation of 11 young children with various language, behavior, and social deficits. ${ }^{6}$ Autistic disorder is now one of five pervasive developmental disorders defined in the Diagnostic and Statistical Manual of Mental Disorders, Fourth Edition, Text Revision (DSM-IV-TR). ${ }^{7}$ The other pervasive developmental disorders are Asperger syndrome, pervasive developmental disorder-otherwise not specified (PDD-NOS), Rett syndrome, and childhood disintegrative disorder. Autistic disorder is also included in the diagnostic category of autistic spectrum disorders, along with two other pervasive developmental disorders, ie, Asperger syndrome and PDD-NOS, due to similarities in the characteristics of the disorders. ${ }^{8,9}$

\section{Etiology and epidemiology}

Autistic disorder is a neurodevelopmental disorder that has a strong genetic influence, with possible environmental contributors. ${ }^{10}$ However, its exact cause is not known. A high percentage of children with autistic disorder have macrocephaly, with rapid increases in head circumference at 6-14 months of age. ${ }^{10,11}$ Neuroimaging studies have found increases in total brain volume among children with autistic disorder, with increases seen in the cerebellum and cerebrum. This growth is most pronounced in areas of the brain (frontal, temporal, and cerebellar regions) that are responsible for language, cognition, and social behavior. It has been suggested that this increase in brain volume may result in a less organized and inefficiently functioning brain. ${ }^{10,12}$

Most epidemiologic studies have looked at the occurrence of autistic spectrum disorders, rather than autistic disorder alone. For autistic spectrum disorders, a rate of six per 1000 has been considered as a best estimate. ${ }^{8}$ In 2009, the Centers for Disease Control and Prevention published the 2006 results from the Autism and Developmental Disabilities Monitoring Network surveillance study on the prevalence of autistic spectrum disorders in the US. ${ }^{13}$ Nearly 308,000 children, eight years of age and living in 11 different states, were included in the surveillance study. Data from health (DSM-IV-TR or ICD-9 billing codes) and educational (eg, special education eligibility classification) sources were used to identify children with a diagnosis of autistic spectrum disorder. The overall prevalence was nine per 1000 children at eight years of age, for an average increase of $57 \%$ from a previous 2002 surveillance study. In most states, autistic disorder accounted for the majority of autistic spectrum disorder diagnoses.

\section{Signs and symptoms}

Autistic disorder affects three core domains in functioning, ie, socialization, communication, and behavior. ${ }^{9}$ Clinical signs are present early in life (as early as 6-12 months), but are frequently not recognized as possible indicators of autistic disorder.

\section{Socialization}

Socialization among children with autistic disorder is described as poor, with a general lack of interest in connectedness with others. ${ }^{8}$ Joint attention, the desire to share an object or event with another in early development, is often delayed or absent. Other aspects of socialization, such as response to name, eye-to-eye contact, nonverbal behavior for interactions with others, and social reciprocity, are also deficient in children with autistic disorder. ${ }^{8,9}$

\section{Communication}

Communication in children with autistic disorder is impaired on several levels. Lack of speech is a classic sign of autistic disorder, especially when there is a lack of desire for connectedness with others. ${ }^{8}$ When present, speech can be noncommunicative and "scripted", repetitive, or out of context.

\section{Behavior}

Behavior in children with autistic disorder is often restricted and stereotyped. ${ }^{9}$ This may include repetitive behaviors such as hand flapping, rocking, or twirling, as well as strict adherence to routines. ${ }^{8,9}$ Interests may be limited to certain topics or activities, with some degree of preoccupation and/or obsession. In addition to these behaviors, children with autistic disorder often have accompanying emotional problems that may further affect behavior and interfere with development. ${ }^{14}$

\section{Diagnosis}

The diagnosis of autistic disorder is based on abnormal or impairment of development in the three core domains of socialization, communication, and behavior with differentiation from other pervasive developmental disorders. The DSM-IV-TR criteria are given in Table $1 .^{7}$ 
Table I DSM-IV-TR diagnostic criteria for autistic disorder ${ }^{7}$

Six or more of the following, meeting at least two criteria under social interactions and one under communication:

Social interactions

Marked impairment of nonverbal behaviors (eye-to-eye gaze, facial expression, body postures, and gestures)

Failure to develop appropriate peer relationships

Lack of spontaneous seeking of connectedness (sharing enjoyments, interests, or achievements with others)

Lack of social or emotional reciprocity

Communication

Delay or lack of development of speech, without attempts at alternate methods of communication (eg, gesture, mime)

Inability to initiate or sustain a conversation with others (when speech is adequate)

Stereotyped and repetitive use of language or idiosyncratic language Lack of appropriate varied, spontaneous make-believe play or social imaginative play

Behavior

Restricted or repetitive and stereotyped patterns of behavior, interests, and activities:

Preoccupation with one or more stereotyped and restricted patterns of interest that is abnormal in intensity or focus Inflexible adherence to specific/nonfunctional routines

Stereotyped and repetitive mannerisms (hand flapping/twisting, whole body movements)

Persistent preoccupation with parts of objects

Delays or abnormal functioning in at least one of the following, with onset before age three years:

Social interaction

Language for social communication

Symbolic or imaginative play

Impairments are not due to either Rett syndrome or childhood disintegrative disorder

Abbreviation: DSM-IV-TR, Diagnostic and Statistical Manual of Mental Disorders, Fourth Edition, Text Revision.

\section{Issues with management of autistic disorder}

Treatment of children with autistic disorder focuses on the core domains affected and associated deficits or emotional problems. ${ }^{9,15}$ Various approaches to treatment of autistic disorder have been used, including educational and behavioral interventions (eg, applied behavioral analysis, structured teaching, developmental-based models, communicationbased programs, and social skills instruction), speech, language and occupational therapy, and pharmacologic therapy. ${ }^{15,16}$ Results of surveys of parents on interventions used in the treatment of autistic disorder found pharmacologic therapies were tried by about half and included antipsychotics, antidepressants, mood stabilizers, and stimulants. ${ }^{1,17}$

However, autistic disorder can manifest with a wide spectrum of maladaptive or destructive behaviors, which can often fluctuate from day to day. ${ }^{1,15}$ In addition, autistic disorder can be associated with other medical problems, such as epilepsy and gastrointestinal disturbances, as well as psychiatric conditions (eg, depression, phobias, obsessive-compulsive disorder) ${ }^{18-21}$ Therefore, children with autistic disorder often receive multiple therapies for multiple problems, making it difficult to determine the most effective interventions.

Maladaptive or destructive behavior in children with autistic disorder often manifests as irritability, including self-injurious behavior, temper tantrums, aggression, and nervousness. ${ }^{4,14}$ Lecavalier reported parents' and teachers' identification of moderate to severe behavioral and emotional problems in children with pervasive developmental disorder, based on the Nisonger Child Behavior Rating Form (NCBRF), a standardized instrument designed to assess child and adolescent behavior. The NCBRF rates social competence items distributed on subscales of conduct problem, insecure/anxious, hyperactive, self-injury/stereotypic, selfisolated/ritualistic, and overly sensitive or irritable. Based on parent and teacher observations, temper tantrums were present in $30 \%$ of children, nervousness in $20 \%$, irritability in $20 \%$, and self-injury in $11 \%$. These problems were present in similar proportions in a subgroup of children with autism. Hartley et al conducted a similar study, using the Childhood Behaviour Checklist (CBCL) to identify maladaptive behaviors in 169 children with autistic disorder. ${ }^{22}$ Based on caregiver assessments, clinically significant scores were seen in the CBCL scales of withdrawn (70.4\%), attention (38.5\%), and aggression $(22.5 \%)$. The authors noted that these specific behaviors may greatly interfere with early treatment interventions, limiting the success of the intervention.

\section{Aripiprazole Mechanism of action}

Aripiprazole is an atypical antipsychotic indicated for the treatment of schizophrenia, bipolar disorder, major depression, and irritability associated with autistic disorder. ${ }^{23}$ Compared with other atypical antipsychotics, the mechanism of action of aripiprazole is unique. ${ }^{24}$ Atypical antipsychotics have been classified based on their affinity for serotonin (5-HT) and/or dopamine (D) receptors. These classifications include multiacting receptor-targeted (eg, 5-HT, $\mathrm{D}_{2}$, cholinergic, and histaminergic receptors) antipsychotics, such as clozapine, olanzapine, and quetiapine; serotonin-D receptor antagonists, such as iloperidone, risperidone, and ziprasidone; and combined $\mathrm{D}_{2} / \mathrm{D}_{3}$ receptor antagonists, such as amisulpride, remoxipride, and sulpiride. Aripiprazole, however, is a partial D receptor agonist, with a high affinity for $\mathrm{D}_{2}$ and $\mathrm{D}_{3}$ receptors, exerting both 
agonist and antagonist activities at the receptor. ${ }^{23,24}$ When dopaminergic activity is low, aripiprazole exhibits agonist activity (with $30 \%$ to $40 \%$ of intrinsic $\mathrm{D}_{2}$ receptor agonism), but, in the presence of high dopaminergic activity, aripiprazole is an antagonist. ${ }^{25,26}$ In addition to the level of D activity, the ratio of agonist to antagonist activity on $\mathrm{D}$ receptors is thought to be influenced by the location, function, and density of the D receptors themselves, and has been referred to as "functional selectivity". ${ }^{24,25,27}$ This agonist/antagonist activity of aripiprazole may also account for its lower incidence of extrapyramidal symptoms and prolactin effects compared with other atypical antipsychotics. Aripiprazole appears to occupy $\mathrm{D}_{2}$ receptors at a high enough rate for a therapeutic response, but below that needed to induce extrapyramidal symptoms or elevate prolactin levels. ${ }^{25,27,28}$ In contrast, atypical antipsychotics classified as multiacting receptor-targeted antipsychotics or serotonin-D receptor antagonists may have moderate extrapyramidal symptom-inducing effects. ${ }^{24}$ Aripiprazole also exhibits antagonist activity at the $5-\mathrm{HT}_{2 \mathrm{~A}}$ receptor and partial agonist activity at $5-\mathrm{HT}_{1 \mathrm{~A}}$ and $5-\mathrm{HT}_{2 \mathrm{C}}$ receptors, which may contribute to its lower risk of weight gain compared with other atypicals. ${ }^{23,25,27}$

\section{Aripiprazole and autistic disorder}

Most research on the mechanism of action of aripiprazole has focused on its efficacy in the treatment of the negative and positive symptoms of schizophrenia. ${ }^{29}$ However, the negative symptoms of schizophrenia (diminished social functioning and communication, decreased emotional expression, and impaired concentration) are similar to many of the functional impairments in communication and socialization seen in autistic disorder. ${ }^{7,30}$ Also similar to schizophrenia, disruptions in serotonin synthesis and dopaminergic systems have been suggested as factors in the development of autistic disorder. ${ }^{31-35}$ This is supported by studies that have reported abnormalities in both serotonin and D transporter binding in adults with autistic disorder. Research also suggests that reductions in serotonergic and increases in dopaminergic systems may correlate with repetitive and aggressive behaviors, respectively. ${ }^{36}$

\section{Efficacy of aripiprazole in autistic disorder}

A number of reports and studies have been published that describe the use and efficacy of aripiprazole for treatment of irritability and related maladaptive or disruptive behaviors in children with autistic disorder.

\section{Case reports}

Stigler et al described the effect of aripiprazole in the treatment of aggressive behavior in a case series of five children and adolescents (mean age 12.2 years) with pervasive developmental disorder. ${ }^{37}$ Maladaptive behaviors included irritability, aggression, agitation, self-injurious behavior, and temper tantrums. Four of the five patients met the criteria for and had been diagnosed with autistic disorder. The remaining patient had been diagnosed with Asperger syndrome and also exhibited aggressive and impulsive behaviors. Previous treatments used included atypical antipsychotics (risperidone and olanzapine), selective serotonin reuptake inhibitors (fluoxetine, fluvoxamine, clomipramine, sertraline, and paroxetine), stimulants (methylphenidate and amphetamines), clonidine, and guanfacine. However, these therapies were discontinued either due to lack of efficacy or tolerability. Aripiprazole was started at a dose of 5 to $10 \mathrm{mg}$ at bedtime, and increased based on symptom response and tolerability. Efficacy was assessed based on Clinical Global Impressions-Improvement (CGI-I) scores, with response defined as "much improved" or "very much improved". All five patients responded to aripiprazole at doses of 10 or $15 \mathrm{mg}$ at bedtime (mean $12 \mathrm{mg}$ ). Aggressive behaviors, including self-injurious behavior, were reduced in all patients. Treatment was well tolerated; two patients had mild sedation. The largest weight gain reported was $1 \mathrm{lb}$; two patients lost weight, and the remaining patients had no change in weight.

\section{Open-label trials}

Malone et al presented the findings of an open-label pilot study involving 11 children and adolescents (mean age $15.3 \pm 2.2$ years) with autistic disorder. ${ }^{38}$ Aripiprazole (dose not specified) was given for six weeks, without other psychotropic medications. Changes from baseline in the CGI-I ratings and the Children's Psychiatric Rating Scale-14 (CPRS) and subscales were used to assess efficacy. Of nine evaluable patients, seven (77\%) were considered responders (much or very much improved) based on CGI-I scores. For other endpoints assessed, the CPRS-14 and the CPRS anger subscale both showed a trend in favor of aripiprazole.

\section{Randomized controlled trials}

Marcus et al conducted a randomized, double-blind trial comparing a fixed dose of aripiprazole with placebo. ${ }^{39}$ Children and adolescents (aged 5-17 years and weighing $\geq 15 \mathrm{~kg}$ ) with a DMS-IV-TR criteria diagnosis of autistic disorder and aggressive behaviors (irritability, self-injurious behavior, and/or agitation) were eligible for study inclusion. 
Patients were randomized to eight weeks of daily treatment with aripiprazole $5 \mathrm{mg}, 10 \mathrm{mg}$, or $15 \mathrm{mg}$, or placebo. The initial dose of aripiprazole was $2 \mathrm{mg}$ per day and was titrated weekly to achieve the target daily dose; no additional dosage adjustments were made after the target dose was reached. Antianxiety and sleep medications were allowed during the study, and psychotropic medications were used only for acute events. The primary outcome measure was the change from baseline to eight weeks in caregiver-rated Aberrant Behavior Checklist irritability (ABC-I) subscale score. Measures evaluated as secondary outcomes included clinician-rated CGI-I scores, change from baseline in other ABC subscale scores (lethargy/social withdrawal, stereotypy, hyperactivity, and inappropriate speech) and in the Children's Yale-Brown Obsessive-Compulsive scale (CYBOCS, compulsion only), CGI-Severity (CGI-S) scores, and response rate $(\geq 25 \%$ reduction in ABC-I scores and a "much or very much improved" rating in CGI-I scores). Efficacy analyses were conducted using data from all patients who were randomized to treatment, received at least one dose of medication during double-blind treatment, and had at least one baseline versus postrandomization efficacy evaluation.

A total of 218 patients were randomized to treatment; 178 completed the eight-week study. ${ }^{39}$ Efficacy analyses were based on data from 213 patients. Compared with placebo, all doses of aripiprazole resulted in greater improvements in ABC-I scores, with a -8.4 change for placebo, -12.4 for aripiprazole $5 \mathrm{mg},-13.2$ for aripiprazole $10 \mathrm{mg}$, and -14.4 for aripiprazole $15 \mathrm{mg}(P=0.032, P=0.008$, and $P=0.001$ versus placebo, respectively). Significant effects with aripiprazole were seen as early as the second week of treatment. Significant effects in favor of aripiprazole were also seen in CGI-I mean scores at the eighth week, with a greater percentage of patients rated as "much or very much improved" compared with placebo (approximately 55\% versus $35 \%$ ). No difference was seen between placebo and any aripiprazole dose for the $\mathrm{ABC}$ subscale of lethargy/social withdrawal. However, for the stereotypy and hyperactivity subscales, all doses of aripiprazole resulted in significantly greater improvements versus placebo $(P \leq 0$. 05). Only aripiprazole $15 \mathrm{mg}$ was significantly better than placebo for the inappropriate speech subscale $(P \leq 0.001)$ and for changes in CYBOCS (compulsion only; $P \leq 0.05$ ). Treatment differences in CGI-S scores were significantly better with aripiprazole $10 \mathrm{mg}$ and $15 \mathrm{mg}$ compared with placebo $(P \leq 0.05)$. Only aripiprazole $5 \mathrm{mg}$ resulted in a significantly higher response rate compared with placebo $(55.8 \%$ versus $34.7 \%, P=0.034)$. At least one adverse event was reported by the majority of all patients $(>70 \%)$, but overall were mild to moderate. Sedation, somnolence, headache, drooling, tremor, fatigue, extrapyramidal symptoms, and increased appetite were among the more common $(>5 \%)$ adverse events reported with aripiprazole. Weight gain was also seen with aripiprazole. Clinically relevant weight gains $(\geq 7 \%)$ were reported by $8.2 \%, 32.7 \%$ ( $P<0.005$ versus placebo), $15.3 \%$, and $30.2 \%(P<0.005$ versus placebo $)$ of patients in the placebo and aripiprazole $5 \mathrm{mg}, 10 \mathrm{mg}$, and $15 \mathrm{mg}$ dose groups, respectively.

A similar study was conducted by Owen using a flexible dose regimen of aripiprazole. ${ }^{40}$ Ninety-eight children and adolescents (aged 6-17 years and weighing $\geq 15 \mathrm{~kg}$ ) meeting DMS-IV TR criteria for autistic disorder with aggressive behaviors were randomly assigned to treatment with either placebo or aripiprazole for an eight-week treatment period. Aripiprazole was initiated at $2 \mathrm{mg}$ per day, and titrated weekly to a target dose of $5 \mathrm{mg}$, $10 \mathrm{mg}$, or $15 \mathrm{mg}$ during the first six weeks. Antianxiety and sleep medications were allowed, but psychotropic medications were discontinued prior to the start of the study. Primary and secondary outcomes and the population evaluated for efficacy were the same as in the study by Marcus et al. ${ }^{39}$

Seventy-five patients completed the eight-week study; and 85 were included in the efficacy evaluation. ${ }^{40}$ At week $8,5 \%$ of the aripiprazole group were receiving $2 \mathrm{mg}$ per day, $33 \%$ were on $5 \mathrm{mg}, 41 \%$ on $10 \mathrm{mg}$, and $21 \%$ on $15 \mathrm{mg}$. A significant reduction was seen in the caregiver-rated ABC-I subscale score (the primary outcome) with aripiprazole compared with placebo ( -12.9 versus $-5.0, P<0.001)$, with significance seen during week 1 of treatment. Mean CGI-I scores were also significantly improved with aripiprazole compared with placebo $(P<0.001)$. At week $8,67 \%$ of the aripiprazole group was considered "much or very much improved" versus $16 \%$ of the placebo group, based on clinician-rated CGI-I scores. For other secondary outcomes (ABC subscales for hyperactivity, stereotypy, and inappropriate speech, CGI-S scores, and CYBOCS [compulsion only]), aripiprazole resulted in significant improvements compared with placebo ( $P<0.001$ for all comparisons). Aripiprazole also resulted in a higher response rate, based on a $\geq 25 \%$ reduction in ABC-I subscale scores and CGI-I scores of "much or very much improved" (52.2\% versus $30.4 \%$ for placebo). At least one adverse event was reported by $72 \%$ of the placebo group and $91.5 \%$ of the aripiprazole group. Somnolence, sedation, fatigue, drooling, tremor, increased appetite, and extrapyramidal symptoms were the most common events in the aripiprazole group. Weight gain was also higher in the aripiprazole group, with $28.9 \%$ of patients 
having a $\geq 7 \%$ weight gain from baseline compared with $6.1 \%$ with placebo.

\section{Safety and tolerability}

Although the atypical antipsychotics, including aripiprazole, are often prescribed to children and adolescents, there remains a paucity of specific atypical antipsychotic safety data in the pediatric population. ${ }^{41}$ Pediatric data on the safety and tolerability of the atypical antipsychotics are normally inferred from adult data. These adult data have generally concluded that the atypicals are better tolerated than traditional typical antipsychotics. However, in the pediatric population, safety concerns may be amplified because the effects of the atypical antipsychotics on the developing brain are largely unknown, and children with psychiatric conditions may undergo lifelong therapy.

\section{Metabolic adverse events}

In 2009, a review of 100 spontaneous reports of pediatric metabolic adverse events involving five atypical antipsychotics (ie, aripiprazole, olanzapine, quetiapine, risperidone, and ziprasidone) was conducted by the Food and Drug Administration (FDA) Office of Pediatric Therapeutics. ${ }^{42}$ All reports were received through the FDA Adverse Event Reporting System from September 1, 2008 to August 31, 2009 and detailed instances of various metabolic events such as Type 1 or 2 diabetes, weight gain, and hyperlipidemia or hypertriglyceridemia. A summary of the reviewed data is presented in Table 2. This data review led to a recommendation by the FDA Pediatric
Advisory Committee that additional information regarding weight gain be added to the aripiprazole product labeling. ${ }^{43}$

Specific clinical data on the cardiometabolic risks of atypical antipsychotics in pediatrics are limited. However, the Second-Generation Antipsychotic Treatment Indications, Effectiveness and Tolerability in Youth (SATIETY) trial provides some information on these risks. ${ }^{44}$ This nonrandomized cohort study involved 338 pediatric patients (aged 4-19 years) who were first-time users of atypical antipsychotics. Enrolled patients had a history of mood, schizophrenic, or disruptive/aggressive behavioral symptoms and were treated with either aripiprazole $(n=47)$, olanzapine $(n=52)$, quetiapine $(n=45)$, or risperidone $(n=168)$ for 12 weeks. Twenty patients served as an untreated comparison group. Primary endpoints included absolute and relative weight change. Changes in body composition and fasting metabolic parameters were among the secondary outcomes measured.

Of the enrolled patients, 272 underwent at least one postbaseline assessment, and 205 completed the study in its entirety. ${ }^{44}$ Results revealed that olanzapine therapy was associated with the highest mean weight gain $(8.5 \mathrm{~kg})$ followed by quetiapine $(6.1 \mathrm{~kg})$, risperidone $(5.3 \mathrm{~kg})$, and aripiprazole $(4.4 \mathrm{~kg})$ after a median of 10.8 weeks of treatment. This compared with a weight gain of $0.2 \mathrm{~kg}$ in the untreated group. In addition, all of the atypicals were associated with significant increases in fat mass, waist circumference, and shifts to both overweight or obese status among enrolled patients. Changes in selected metabolic parameters over the 12-week study period are summarized in Table 3.

Table 2 Summary of pediatric metabolic adverse event reports for five atypical antipsychotics ${ }^{42}$

\begin{tabular}{|c|c|c|c|}
\hline $\begin{array}{l}\text { Atypical } \\
\text { antipsychotic }\end{array}$ & $\begin{array}{l}\text { Adverse } \\
\text { events (n) }\end{array}$ & $\begin{array}{l}\text { Age range } \\
\text { (years); gender }\end{array}$ & Overview of metabolic adverse event reporting \\
\hline Aripiprazole & 33 & 6 to $17 ; 24 \mathrm{M}, 8 \mathrm{~F}, \mathrm{IU}$ & $\begin{array}{l}22 \text { weight gain } \\
5 \text { hospitalizations ( } 2 \text { for hyperglycemia) } \\
3 \text { diabetes } \\
8 \text { other metabolic events (ie, hyperlipidemia) }\end{array}$ \\
\hline Olanzapine & 7 & 12 to $17 ; 3 \mathrm{M}, 4 \mathrm{~F}$ & $\begin{array}{l}4 \text { hospitalizations } \\
3 \text { diabetes } \\
\text { I each of death, weight gain, pancreatitis, and } \\
\text { hyperprolactinemia }\end{array}$ \\
\hline Quetiapine & 48 & 6 to $17 ; 20 \mathrm{M}, 28 \mathrm{~F}$ & $\begin{array}{l}36 \text { diabetes } \\
13 \text { weight gain } \\
5 \text { deaths (no causal relationship to therapy) } \\
\text { I underwent gastric bypass }\end{array}$ \\
\hline Risperidone & 11 & 6 to $17 ; 4 \mathrm{M} ; 7 \mathrm{~F}$ & $\begin{array}{l}7 \text { diabetes } \\
4 \text { weight gain } \\
3 \text { hospitalizations (behavioral effects and hyperglycemia) }\end{array}$ \\
\hline Ziprasidone & I & I3; IM & $\begin{array}{l}\text { I report of diabetes, hyperlipidemia, and hypertriglyceridemia } \\
\text { with hospitalization for injurious behavior }\end{array}$ \\
\hline
\end{tabular}

Abbreviations: $M$, males; $F$, females; $U$, unknown. 
Table 3 Changes in selected metabolic parameters in the SecondGeneration Antipsychotic Treatment Indications, Effectiveness and Tolerability in Youth trial ${ }^{44}$

\begin{tabular}{|c|c|c|}
\hline $\begin{array}{l}\text { Atypical } \\
\text { antipsychotic }\end{array}$ & $\begin{array}{l}\text { Metabolic parameter } \\
\text { (mean change from } \\
\text { baseline }[95 \% \mathrm{Cl}] \text { ) }\end{array}$ & $\begin{array}{l}P \text { value } \\
\text { versus } \\
\text { baseline }\end{array}$ \\
\hline \multicolumn{3}{|c|}{ Glucose (mg/dL) } \\
\hline Aripiprazole & $0.54(-2.85-3.93)$ & 0.76 \\
\hline Olanzapine & $3.14(0.69-5.59)$ & 0.02 \\
\hline Quetiapine & $2.64(-0.65-5.93)$ & 0.12 \\
\hline Risperidone & $1.14(-0.84-3.12)$ & 0.26 \\
\hline Untreated & $0.69(-4.84-6.22)$ & 0.81 \\
\hline \multicolumn{3}{|c|}{ Insulin $(\mu \mid \mathrm{U} / \mathrm{mL})$} \\
\hline Aripiprazole & $2.6 \mathrm{I}(-2.09-7.3 \mathrm{I})$ & 0.28 \\
\hline Olanzapine & $2.71(0.42-5.00)$ & 0.02 \\
\hline Quetiapine & $1.08(-2.80-4.96)$ & 0.59 \\
\hline Risperidone & $0.69(-0.86-2.24)$ & 0.39 \\
\hline Untreated & $-0.47(-4.31-3.37)$ & 0.81 \\
\hline \multicolumn{3}{|c|}{ Total cholesterol (mg/dL) } \\
\hline Aripiprazole & $3.75(-3.85-11.35)$ & 0.34 \\
\hline Olanzapine & $15.58(6.88-24.28)$ & $<0.001$ \\
\hline Quetiapine & $9.05(0.4 I-17.69)$ & 0.046 \\
\hline Risperidone & $3.46(-1.44-8.36)$ & 0.17 \\
\hline Untreated & $2.38(-7.69-12.45)$ & 0.82 \\
\hline \multicolumn{3}{|c|}{ LDL cholesterol (mg/dL) } \\
\hline Aripiprazole & $7.38(0.77-13.99)$ & 0.05 \\
\hline Olanzapine & $11.54(3.97-19.11)$ & 0.004 \\
\hline Quetiapine & $3.88(-3.37-11.13)$ & 0.30 \\
\hline Risperidone & $0.21(-4.14-4.56)$ & 0.92 \\
\hline Untreated & $2.99(-5.18-11.16)$ & 0.49 \\
\hline \multicolumn{3}{|c|}{ HDL cholesterol (mg/dL) } \\
\hline Aripiprazole & $0.29(-2.32-2.90)$ & 0.83 \\
\hline Olanzapine & $-1.27(-3.80-1.26)$ & 0.33 \\
\hline Quetiapine & $-1.47(-5.06-2.12)$ & 0.43 \\
\hline Risperidone & $0.33(-1.26-1.92)$ & 0.68 \\
\hline Untreated & $1.49(-3.10-6.08)$ & 0.53 \\
\hline \multicolumn{3}{|c|}{ Triglycerides (mg/dL) } \\
\hline Aripiprazole & $-2.40(-|9.7|-|4.9|)$ & 0.79 \\
\hline Olanzapine & $24.34(9.80-38.88)$ & 0.002 \\
\hline Quetiapine & $36.96(10.13-63.79)$ & 0.01 \\
\hline Risperidone & $9.74(0.45-19.03)$ & 0.04 \\
\hline Untreated & $-11.84(-41.55-17.87)$ & 0.45 \\
\hline
\end{tabular}

Abbreviations: LDL, low-density lipoprotein; HDL, high-density lipoprotein; $\mathrm{Cl}$, confidence interval.

The aripiprazole and untreated comparator arms were the only groups to record nonsignificant changes from baseline for all parameters; however, aripiprazole therapy did result in a near significant increase in low-density lipoprotein cholesterol levels.

The negative effects on weight gain and metabolic parameters observed in the 12-week SATIETY trial confirm the highly vulnerable nature of the pediatric population for these adverse events. ${ }^{44,45}$ Extreme weight gain and elevations in serum glucose and cholesterol early in life may eventually lead to a wide range of comorbidities, including hypertension, coronary artery disease, stroke, respiratory problems, diabetes, and hyperlipidemia. ${ }^{45,46}$ Given the serious health risks involved, the American Diabetes Association in association with the American Psychiatric Association, American Association of Clinical Endocrinologists, and the North American Association for the Study of Obesity recommend that patients on atypical antipsychotics be monitored frequently for changes in weight, blood pressure, serum glucose, and serum lipids (Table 4). ${ }^{47}$

Based on SATIETY trial data, aripiprazole appears to be associated with the lowest incidence of weight gain and adverse metabolic events in the pediatric patient population. ${ }^{44}$ However, these data, along with reports associating aripiprazole with the induction of diabetic ketoacidosis and hyperglycemia, should emphasize to prescribers the continued need to monitor pediatric patients receiving aripiprazole closely for metabolic effects. ${ }^{48,49}$

\section{Extrapyramidal effects}

Atypical antipsychotics, including aripiprazole, are generally associated with a reduced risk of extrapyramidal symptoms (ie, tremor, dystonia, akathisia, cogwheel rigidity) than typical antipsychotics. ${ }^{50,51}$ Pediatric patients may, however, experience an increased degree of antipsychotic-related extrapyramidal symptoms as compared with adults, due to higher $\mathrm{D}_{2}$ receptor densities in the brain. ${ }^{51}$

Wonodi et al evaluated the prevalence of tardive dyskinesia among children and adolescents (aged 5-18 years) receiving atypical antipsychotics over a three-year period in the greater Baltimore area. ${ }^{52}$ Of 424 pediatric patients who were screened for psychotropic-induced adverse events at various treatment facilities, 118 who received antipsychotic therapy for $\geq$ six months and 80

Table 4 Recommended monitoring for metabolic adverse events for patients receiving atypical antipsychotics ${ }^{\mathrm{a}, 47}$

\begin{tabular}{ll}
\hline Monitoring period & Assessments \\
\hline Baseline & $\begin{array}{l}\text { Personal/family history, BMI, waist } \\
\text { circumference, blood pressure, fasting } \\
\text { plasma glucose and lipid profile }\end{array}$ \\
4 weeks & BMI \\
8 weeks & BMI \\
I2 weeks & BMI, blood pressure, fasting plasma glucose, \\
& and lipid profile \\
Quarterly & BMI \\
Annually & Personal/family history, waist circumference, \\
Every 5 years & blood pressure, fasting plasma glucose \\
\hline
\end{tabular}

Note: a More frequent assessments may be necessary based upon the clinical profile of the patient.

Abbreviation: BMI, body mass index. 
who were antipsychotic therapy-naïve were included in the analysis. Of the 118 patients who were actively treated, 81 received atypical antipsychotic therapy only. In addition, the investigators included 35 healthy controls with no history of either psychiatric disorders or psychotropic therapy in the trial.

Results revealed a significantly higher rate of tardive dyskinesia among antipsychotic-treated (9\%) than in antipsychotic-naïve $(0 \%)$ pediatric patients $(P=0.003)$ with the risk increasing according to duration of therapy, ie, 3\% within 6-12 months of treatment, 10\% within 1-2 years, and in $14 \%$ treated for more than two years. ${ }^{52}$ Of the 81 pediatric patients who had only received an atypical antipsychotic agent, five (6\%) exhibited significant dyskinesia compared with none in the antipsychotic-naïve group $(P=0.05)$. Similarly, no patients in the healthy control group exhibited signs or symptoms of tardive dyskinesia during the study.

Beyond the data in the aforementioned pediatric study, there have also been isolated case reports detailing the development of extrapyramidal symptoms in children and adolescents receiving aripiprazole. ${ }^{53-55}$

\section{Cardiac effects}

Although other atypical antipsychotics are associated with adverse cardiac effects, such as QT prolongation, the aripiprazole product labeling does not mention negative cardiac effects associated with use. ${ }^{23}$ In fact, long-term trials in adults imply that aripiprazole therapy may shorten the QT interval. ${ }^{56}$ Despite these data, there are reports of aripiprazole-induced cardiac arrhythmia and symptomatic bradycardia. ${ }^{57,58}$ Therefore, prescribers should be aware of the potential for these adverse cardiac effects.

\section{Other safety concerns}

Sedation/somnolence is a common adverse effect with the use of any atypical antipsychotic medication. ${ }^{51}$ In some clinical trials involving aripiprazole in pediatric patients, the incidence of this effect was reported to be as high as 50\%-78\% in enrolled subjects. ${ }^{50}$ Other common ( $\left.\geq 10 \%\right)$ adverse effects among aripiprazole-treated pediatric patients include nausea, vomiting, gastrointestinal upset, and headache. In an openlabel, multicenter, dose-escalation tolerability trial involving 21 children and adolescents with bipolar or schizophrenic disorders, aripiprazole was found to be generally well tolerated, with the most commonly reported adverse effects including upper abdominal pain, headache, dizziness, and vomiting. 59
Generally, atypical antipsychotic therapy leads to an increase in prolactin levels. However, aripiprazole has been shown to reduce prolactin and may actually reverse symptomatic hyperprolactinemia in some cases. ${ }^{50,60}$ Aripiprazole has also been linked to the potential development of neuroleptic malignant syndrome in children. ${ }^{61-63}$ Finally, another potential concern is the development of treatment-emergent mania or hypomania, which has been observed in pediatric patients receiving other atypical antipsychotics. ${ }^{41}$

\section{Patient-focused perspectives}

Other important considerations when evaluating atypical antipsychotic treatments include the effects on quality of life (QOL) and patient satisfaction. In a randomized, double-blind trial by Marcus et al who compared fixed-dose aripiprazole $5 \mathrm{mg}, 10 \mathrm{mg}$, or $15 \mathrm{mg}$ daily with placebo in 218 children and adolescents with autistic disorder and aggressive behaviors, the patients' and caregivers' assessments of QOL were evaluated. ${ }^{39}$ For patients, the Pediatric Quality of Life Inventory (PedsQL) was used to evaluate change in QOL from baseline to endpoint. The Caregiver Strain Questionnaire (CGSQ) was performed to rate family strain over the preceding three-month period. Results revealed that the $15 \mathrm{mg}$ dose of aripiprazole was associated with a significant improvement in both the mean PedsQL score (least squares mean treatment difference $8.2 ; 95 \%$ CI 1.2 to 15.2 ) and the CGSQ score (treatment difference -1.1 ; 95\% CI -1.9 to -0.3$)$. No significant improvements were observed with the $5 \mathrm{mg}$ and $10 \mathrm{mg}$ aripiprazole doses as compared with placebo. Even though the $15 \mathrm{mg}$ daily dose resulted in QOL improvements, the investigators cautioned that longer-term data are needed, with flexible dosage regimens, to determine fully the applicability of these results in clinical practice.

Owen et al performed similar QOL assessments in a randomized, double-blind, flexible dose, eight-week study involving 98 children and adolescents with autistic disorder and aggressive behaviors. ${ }^{40}$ The QOL outcomes were assessed at baseline and week 8 . Results showed that aripiprazole therapy was associated with an improvement in both PedsQL score (treatment difference 11.4; 95\% CI 6.1 to 16.8 ) and CGSQ score (treatment difference $-1.9 ; 95 \%$ $\mathrm{CI}-2.7$ to -1.2 ) as compared with placebo.

\section{Conclusions}

Autistic disorder remains a challenging condition for health care providers to not only treat, but also to understand with regard to etiology and pathophysiology. Aripiprazole is an atypical antipsychotic which has recently 
received approval for the management of irritability associated with autistic disorder. Currently, efficacy data for aripiprazole in pediatric patients with autistic disorder are limited. However, existing published case reports, open-label trials, and randomized, placebo-controlled trials suggest that aripiprazole may reduce irritability and aggressive, injurious behaviors. There is also a paucity of safety data for aripiprazole in the pediatric setting. However, the drug appears to have the least effect on weight gain and metabolic parameters, such as glucose and lipid levels, as compared with other available atypical antipsychotics. Health care providers should monitor patients for other potential adverse effects, including extrapyramidal symptoms, sedation, gastrointestinal issues, and headache. Finally, QOL data, albeit limited, suggest that aripiprazole therapy is associated with improvements in both patient and caregiver QOL.

\section{Disclosure}

The authors report no conflicts of interest in this work.

\section{References}

1. Goin-Kochel R, Mackintosh V, Myers B. Parental reports on the efficacy of treatments and therapies for their children with autism spectrum disorders. Res Autism Spectr Disord. 2009;3(2): 528-537.

2. Committee on Children with Disabilities. American Academy of Pediatrics. Technical report: The pediatrician's role in the diagnosis and management of autistic spectrum disorder in children. Pediatrics. 2001;107(5):1221-1226.

3. Geschwind D. Advances in autism. Annu Rev Med. 2009;60: 367-380.

4. Stigler K, McDougle C. Pharmacotherapy of irritability in pervasive developmental disorders. Child Adolesc Psychiatr Clin N Am. 2008;17(4):739-752.

5. Malone R, Waheed A. The role of atypical antipsychotics in the management of behavioural symptoms in children and adolescents with autism. Drugs. 2009;69(5):535-548.

6. Kanner L. Autistic disturbances of affective contact. Nerv Child. 1943;2:217-250.

7. American Psychiatric Association. Diagnostic and Statistical Manual of Mental Health Disorders DSM-IV-TR. 4th ed. Washington, DC: American Psychiatric Association; 2000.

8. Johnson C, Myers S, Council on Children with Disabilities. Identification and evaluation of children with autism spectrum disorders. Pediatrics. 2007;120(5):1183-1215.

9. Levy S, Mandell D, Schultz R. Autism. Lancet. 2009;374(9701): 1627-1638.

10. Shah P, Dalton R, Boris N. Pervasive developmental disorders and childhood psychosis. In: Kliegman R, Behrman R, Jenson H, Stanton B, editors. Nelson Textbook of Pediatrics. 18th ed. Philadelphia, PA: Saunders Elsevier; 2007.

11. Verhoeven J, DeCock P, Lagae L, Sunaert S. Neuroimaging of autism. Neuroradiology. 2010;52(1):3-14.

12. Stanfield A, McIntosh A, Spencer M, Philip R, Gaur S, Lawrie S. Towards a neuroanatomy of autism: A systematic review and metaanalysis of structural magnetic resonance imaging studies. Eur Psychiatry. 2008;23(4):289-299.
13. Autism and Developmental Disabilities Monitoring Network 2006 Principal Investigators; Centers for Disease Control and Prevention (CDC). Prevalence of autism spectrum disorders - autism and developmental disabilities monitoring network, United States, 2006. MMWR Surveill Summ. 2009;58(10):1-20.

14. Lecavalier L. Behavioral and emotional problems in young people with pervasive developmental disorders: Relative prevalence, effects of subject characteristics, and empirical classifications. J Autism Dev Disord. 2006;36(8):1101-1114.

15. Myers S, Johnson C, Council on Children with Disabilities. Management of children with autistic spectrum disorders. Pediatrics. 2007;120(5):1162-1182.

16. Ospina M, Seida J, Clark B, et al. Behavioural and developmental interventions for autism spectrum disorders: A clinical systematic review. PloS ONE. 2008;3(11):e3755.

17. Green V, Pituch K, Itchon J, Choi A, O’Reilly M, Sigafoos J. Internet survey of treatments used by parents of children with autism. Res Dev Disabil. 2006;27(1):70-84.

18. Molloy C, Manning-Courtney P. Prevalence of chronic gastrointestinal symptoms in children with autism and autistic spectrum disorders. Autism. 2003;7(2):165-171.

19. Tuchman R, Rapin I. Epilepsy in autism. Lancet. 2002;1(6):352-358.

20. Levy S, Giarelli E, Lee L, et al. Autistic spectrum disorder and cooccurring developmental, psychiatric, and medical conditions among children in multiple populations in the United States. J Dev Behav Pediatr. 2010;31(4):267-275.

21. Leyfer O, Folstein S, Bacalman S, et al. Comorbid psychiatric disorders in children with autism: interview development and rates of disorders. Res Autism Spectr Disord. 2006;36(7):849-861.

22. Hartley S, Sikora D, McCoy. Prevalence and risk factors of maladaptive behaviour in young children with autistic disorder. J Intellect Disabil Res. 2008;52(10):819-829.

23. Abilify [Package insert]. Tokyo, Japan: Otsuka Pharmaceutical Co, Ltd; 2009.

24. Horacek J, Bubenikova-Valesova V, Kopecek M, et al. Mechanism of action of atypical antipsychotic drugs and the neurobiology of schizophrenia. CNS Drugs. 2006;20(5):389-409.

25. Shapiro D, Renock S, Arrington E, et al. Aripiprazole, a novel atypical antipsychotic drug with a unique and robust pharmacology. Neuropsychopharmacology. 2003;28(8):1400-1411.

26. Gründer G, Carlsson A, Wong D. Mechanism of new antipsychotic medications. Arch Gen Psychiatry. 2003;60(10):974-977.

27. Burris K, Molski T, Xu C. Aripiprazole, a novel antipsychotic, is a highaffinity partial agonist in human dopamine D2 receptors. J Pharmacol Exp Ther. 2002;302(1):381-389.

28. Kapur S, Zipursky R, Jones C, Remington G, Houle S. Relationship between dopamine $\mathrm{D}(2)$ occupancy, clinical response, and side effects: A double-blind PET study of first-episode schizophrenia. Am J Psychiatry. 2000;157(4):514-520.

29. Reus V. Mental disorders. In: Fauci A, Braunwald E, Kasper D, et al, editors. Harrison's Internal Medicine. 17th ed. New York, NY: McGraw Hill Companies, Inc; 2008.

30. Esterberg M, Trotman H, Brasfield J, Compton M, Walker E. Childhood and current autistic features in adolescents with schizotypal personality disorder. Schizophr Res. 2008;104(1-3):265-273.

31. Crismon M, Argo T, Buckley P. Schizophrenia. In: Dipiro J, Talbert R, Yee G, Matzke G, Wells B, Posey M, editors. Pharmacotherapy: A Pathophysiologic Approach. 7th ed. New York, NY: McGraw Hill Companies, Inc; 2008.

32. Pardo C, Eberhart C. The neurobiology of autism. Brain Pathol. 2007;17(4):434-437.

33. Chugani D, Muzik O, Behan M, et al. Developmental changes in brain serotonin synthesis capacity in autism and nonautistic children. Ann Neurol. 1999;45(3):285-287.

34. Makkonen I, Riikonen R, Kokki H, Airaksinen M, Kuikka J. Serotonin and dopamine transporter binding in children with autism determined by SPECT. Dev Med Child Neurol. 2008;50(8):593-597. 
35. Volkmaar F, Lord C, Bailey A, Schultz R, Klin A. Autism and pervasive developmental disorders. J Child Psychol Psychiatry. 2004; 45(1):135-170.

36. Nakamura K, Sekine Y, Ouchi Y, et al. Brain serotonin and dopamine transporter bindings in adults with high-functioning autism. Arch Gen Psychiatry. 2010;67(1):59-68.

37. Stigler K, Posey D, McDougle C. Aripiprazole for maladaptive behavior in pervasive developmental disorders. J Child Adolesc Psychopharmacol. 2004;14(3):455-463.

38. Malone R, West S, Ghaffari M, Delaney M, Venditti L. Aripiprazole for the treatment of adolescents with autism: A pilot study [Abstr]. J Child Adolesc Psychopharmacol. 2009;19(6):781.

39. Marcus RN, Owen R, Kamen L, et al. A placebo-controlled, fixeddose study of aripiprazole in children and adolescents with irritability associated with autistic disorder. J Am Acad Child Adolesc Psychiatry. 2009;48(11):1110-1119.

40. Owen R, Sikich L, Marcus R, et al. Aripiprazole in the treatment of irritability in children and adolescents with autistic disorder. Pediatrics. 2009;124(6):1533-1540.

41. Findling RL, Steiner H, Weller EB. Use of antipsychotics in children and adolescents. J Clin Psychiatry. 2005;66 Supp1 7:29-40.

42. Department of Health and Human Services. Clinical summary review of pediatric metabolic adverse events for 5 atypical antipsychotics. Available at: http://www.fda.gov/downloads/AdvisoryCommittees/CommitteesMeetingMaterials/PediatricAdvisoryCommittee/UCM192596.pdf. Accessed Jul 5, 2010.

43. Food and Drug Administration. Minutes of the Pediatric Advisory Committee. 2009 Dec 8. Available at: http://www.fda.gov/downloads/ AdvisoryCommittees/CommitteesMeetingMaterials/PediatricAdvisoryCommittee/UCM197035.pdf. Accessed Jul 5, 2010.

44. Correll CU, Manu P, Olshanskiy V, Napolitano B, Kane JM, Malhotra AK. Cardiometabolic risk of second-generation antipsychotic medications during first-time use in children and adolescents. JAMA. 2009;302(16):1765-1773.

45. Varley CK, McClellan J. Implications of marked weight gain associated with atypical antipsychotic medications in children and adolescents. JAMA. 2009;302(16):1811-1812.

46. Stigler KA, Potenza MN, Posey DJ, McDougle CJ. Weight gain associated with atypical antipsychotic use in children and adolescents. Pediatr Drugs. 2004;6(1):33-44.

47. American Diabetes Association; American Psychiatric Association; American Association of Clinical Endocrinologists; North American Association for the Study of Obesity. Consensus development conference on antipsychotic drugs and obesity and diabetes. Diabetes Care. 2004;27(2):596-601.
48. Dhamija R, Verma R. Diabetic ketoacidosis induced by aripiprazole in a 12-year-old boy. Diabetes Care. 2008;31(6):e50.

49. Logue DD, Gonzalez N, Heligman SDK, McLaughlin JV, Belcher HME. Hyperglycemia in a 7-year-old child treated with aripiprazole. Am J Psychiatry. 2007;164(1):173.

50. Greenaway M, Elbe D. Focus on aripiprazole: A review of its use in child and adolescent psychiatry. J Can Acad Child Adolesc Psychiatry. 2009; 18(3):250-260.

51. McConville BJ, Sorter MT. Treatment challenges and safety considerations for antipsychotic use in children and adolescents with psychoses. J Clin Psychiatry. 2004;65 Suppl 6:20-29.

52. Wonodi I, Reeves G, Carmichael D, et al. Tardive dyskinesia in children treated with atypical antipsychotic medications. Mov Disord. 2007;22(12):1777-1782.

53. Lindsey RL, Kaplan D, Koliatsos V, Waltes JK, Sandso NB. Aripiprazole and extrapyramidal symptoms. J Am Acad Child Adolesc Psychiatry. 2003;42(11):1268-1269.

54. Fountoulakis KN, Siamouli M, Kantartzis S, Panagiotidis P, Lacovides A, St Kaprinis G. Acute dystonia with low-dosage aripiprazole in Tourette's disorder. Ann Pharmacother. 2006;40(4):775-777.

55. Singh MK, Delbello MP, Adler CM. Acute dystonia associated with aripiprazole in a child. J Am Acad Child Adolesc Psychiatry. 2007;46(3):306-307.

56. McGavin JK, Goa KL. Aripiprazole. CNS Drugs. 2002;16(11): 779-786.

57. Torgovnick J, Sethi N, Arsura E. Aripiprazole-induced orthostatic hypotension and cardiac arrhythmia. Psychiatry Clin Neurosci. 2008;62(4):485.

58. Snarr BS, Phan SV, Garner A, VandenBerg AM, Barth KS. Symptomatic bradycardia with oral aripiprazole and oral ziprasidone. Ann Pharmacother. 2010;44(4):760-763.

59. Findling RL, Kauffman RE, Sallee FR, et al. Tolerability and pharmacokinetics of aripiprazole in children and adolescents with psychiatric disorders. J Clin Psychopharmacol. 2008;28(4):441-446.

60. Wahl R, Ostroff R. Reversal of symptomatic hyperprolactinemia by aripiprazole. Am J Psych. 2005;162(8):1542-1543.

61. Hammerman S, Lam C, Caroff SN. Neuroleptic malignant syndrome and aripiprazole. J Am Acad Child Adolesc Psychiatry. 2006;45(6):639-641.

62. Palakurthi HB, Parvin MM, Kaplan S. Neuroleptic malignant syndrome from aripiprazole in an agitated pediatric patient. Clin Neuropharmacol. 2007;30(1):47-51.

63. Groff K, Coffey BJ. Psychosis or atypical neuroleptic malignant syndrome in an adolescent? J Child Adolesc Psychopharmacol. 2008; 18(5):529-532.
Adolescent Health, Medicine and Therapeutics

\section{Publish your work in this journal}

Adolescent Health, Medicine and Therapeutics is an international, peer-reviewed, open access journal focusing on health, pathology, and treatment issues specific to the adolescent age group. All aspects of health maintenance, preventative measures and disease treatment interventions are addressed within the journal and practitioners from

\section{Dovepress}

all disciplines are invited to submit their work as well as healthcare researchers and patient support groups.. The manuscript management system is completely online and includes a very quick and fair peerreview system. Visit http://www.dovepress.com/testimonials.php to read real quotes from published authors. 